delivery can be coordinated at a regional level, taking into account regional priorities and cultural factors. Their emphasis on the community is a refreshing change from the top-down approach of multinational studies whose data seem to have a place only in academic journals and psychiatric institutes rather than the lives of ordinary patients and primary health care providers.

The authors suggest that kufungisisa, or thinking too much, encapsulates the syndrome of depression. However, in our study (in preparation) of 110 patients with conspicuous psychiatric morbidity presenting to general nurses and traditional care providers, this term has been used as a generic term for common mental disorder in over $80 \%$ of cases. The term describes both a phenomenon and a causal model of illness. 'Etic' evaluation with the Revised Clinical Interview Schedule shows that while kufungisisa as a cause is significantly related to etic 'caseness' criteria, it is not specifically related to either depression or anxiety. As a phenomenon, 'thinking too much' seems to be conceptually related to worry. The suggestion that kufungisisa is not related to spiritual causes (as opposed to madness) depends on which care provider is the respondent. Thus, traditional care providers were as likely to perceive a spiritual cause for patients with kufungisisa as for those without, while nurses never considered a spiritual cause for any of their patients. There is not yet evidence to suggest that kufungisisa is equivalent to the Euro-American category of depression.

It is perhaps early to suggest that a model of tackling depression developed in the most urbanised part of Zimbabwe can be generalised to the rural areas, where mental health services are virtually non-existent, and where traditional care providers remain the mainstay of primary mental health care. Even in Harare, up to three-quarters of patients with conspicuous psychiatric morbidity are consulting traditional care providers. A successful intervention programme must take into account their role, concepts and treatment methods, and seek ways of complementing biomedical and traditional health care.

Abas et al have taken more pains in eliciting local views and priorities than many international researchers; only if their message of community-based research is adopted will the knowledge of mental health be culturally valid and understood by the 'front-line' primary health workers.

Department of Psychiatry

University of Zimbabwe

\section{Glucocorticoids, serotonin and mood}

SIR: Dinan has provided a reminder of the possible importance of glucocorticoids in the genesis of depression (BJP, March 1994, 164, 365-372) and stressed that glucocorticoids may produce changes in central monoaminergic function. That glucocorticoids modulate brain monoamine function (particularly brain 5-HT function) has been confirmed in experiments, in both rodents and man (Young et al, 1994). Hypercortisolaemia has been widely reported in depressive disorders as well as other psychiatric disorders (Christie et al, 1986). The question therefore arises as to the possible role of hypercortisolaemia in the pathophysiology of depression.

As Dinan states, there is evidence that in depression blunted 5-HT responses occur in patients who also have higher cortisol levels; this finding suggests that hypercortisolaemia may cause the neurotransmitter abnormalities which give rise to the clinical syndrome. However, high-dose glucocorticoids have been shown to elevate mood briefly in severe depression (Goodwin et al, 1992) and glucocorticoids down-regulate the function of presynaptic $5-\mathrm{HT}_{1 \mathrm{~A}}$ receptors (Young et al, 1994). This action is shared with antidepressant drugs and electroconvulsive shock; thus, it has been suggested it mediates the mood-elevating effects of glucocorticoids (Young et al, 1994). This apparent contradiction may be due to the fact that the hypercortisolaemia of depression is a complex phenomenon which may involve hypothalamic releasing factor hypersecretion, adrenal hypersensitivity to adrenocorticotrophic hormone, pituitary resistance to glucocorticoid feedback, pituitary hypersensitivity to releasing factors, and neural feedback resistance (Sapolsky, 1992).

Hypercortisolaemic depressed patients may be subject to a number of complex neurobiological processes, some of which may be distinct from those effects due to elevated glucocorticoids alone. The key to understanding the genesis of depression may lie in these differing processes and there is a pressing need for further research, both laboratory and clinical, on this subject.

Christie, J. E., Whalley, L. J., Dick, H., et al (1986) Raised plasma cortisol levels a feature of drug free psychotics and not specific for depression. British Journal of Psychiatry, 148, 58-65.

Goodwin, G. M., MuIR, W. J., SeckL, J. R., et al (1992) The effects of cortisol infusion upon hormone secretion from the anterior pituitary and subjective mood in depressive illness and controls. Journal of Affective Disorders, 26, 73-84.

SAPOLSKY, R. M. (1992) Stress, the Aging Brain and Mechanisms of Neuron Death. Cambridge, Massachusetts: MIT Press. 
Young, A. H., Goodwn, G. M., Dick, H., et al (1994) Effects of glucocorticoids on 5-HT 1 presynaptic function in the mouse. Psychopharmacology, 114, 360-365.

Psychopharmacology Research Unit

A. H. Young

Littlemore Hospital

Oxford OX4 4XN

\section{Seizures and antidepressants}

SIR: Curran (BJP, March 1994, 164, 421) states that "Amitriptyline and fluoxetine ... are both associated with a greater propensity to cause seizures in susceptible patients". While it is correct that fluoxetine should be avoided in patients with unstable epilepsy, this does not distinguish fluoxetine from other antidepressants, as Curran's letter suggests.

Maprotoline accounts for $29.9 \%$ of the reports to the Committee on the Safety of Medicines of convulsions during treatment with antidepressants, mianserin $17.3 \%$, fluvoxamine $6.1 \%$ and fluoxetine $2.3 \%$. Amitriptyline accounts for $6.8 \%$ of the total reports (Edwards \& Wheel, 1992). Figures such as these highlight the need to be cautious in prescribing any psychotropic medication to a patient who has epilepsy or is otherwise at risk of seizures.

Curran is incorrect in suggesting that fluoxetine is more likely to induce seizures than other selective serotonin reuptake inhibitors. The letter used as evidence for this statement (Ware \& Stewart, 1989) reports a single patient whose electroencephalogram revealed epileptiform activity before starting fluoxetine. A comprehensive review of seizures associated with antidepressants concludes that fluoxetine has a lower seizure risk than older, tricyclic antidepressants (Rosenstein et al, 1993). Thus, it is quite inaccurate to highlight fluoxetine as particularly epileptogenic.

Edwards, J. G. \& WhEal, H. V. (1992) Assessment of epileptogenic potential: experimental, clinical and epidemiological approaches. Journal of Psychopharmacology, 6, 204-213.

WARE, M. R. \& STEWART, R. B. (1989) Seizures associated with fluoxetine therapy. DICP Annals of Pharmacotherapy, 23, 428.

Rosenstein, D. L., Nelson, J. C. \& Jacobs, S. C. (1993) Seizures associated with antidepressants: a review. Journal of Clinical Psychiatry. 54, 289-299.

\section{Lilly Industries Ltd}

Basingstoke RG21 2SY

JOANNA NAKIELNY

\section{Darier's disease cosegregating with affective disorder}

SIR: We reported a family (pedigree 324 ) in which Darier's disease, a rare autosomal dominant skin disorder, is cosegrating with major affective disorder, and postulated that a susceptibility gene for affective disorder may lie close to and in genetic linkage with the gene for Darier's disease (BJP, March 1994, 164, 355-358). We suggested that when the chromosomal location of the Darier's gene was found, markers from this region should be tested for genetic linkage with bipolar disorder.

We would like to update our report by drawing attention to some recent work of ours carried out in collaboration with colleagues at the Institute of Psychiatry in London and at the Institute for Human Genetics in Bonn.

First, we have mapped the gene for Darier's disease to chromosome 12q23-q24.1 in five British families (including pedigree 324) (Craddock et al, 1993; Parfitt et al, 1994).

Secondly, we have studied a set of highly polymorphic genetic markers from this region to test for genetic linkage in 45 families containing two or more members with bipolar disorder (excluding pedigree 324). We found modest evidence of linkage under heterogeneity using both the traditional lod score method of analysis and also non-parametric sib-pair analysis (Dawson et al, 1994). Our findings do not meet conventional levels required for statistical significance, and we recommend caution when interpreting our results. However, given that there is some a priori evidence for a susceptibility locus for bipolar disorder in this chromosomal region, we would urge other research groups to examine markers from this region in independent sets of bipolar pedigrees.

Finally, we would like to mention one change to the published genogram for pedigree 324 : during follow-up, subject 2.12, the youngest member of the sibship, has shown mild features of Darier's disease. He has not yet had an episode of affective disorder.

Craddock, N., Dawson, E., Burge, S., et al (1993) The gene for Darier's disease maps to chromosome 12q23-q24.1. Human Molecular Genetics, 2, 1941-1943.

Dawson, E., PArfit, E., Roberts, Q., et al (1994) Linkage studies of bipolar disorder in the region of the Darier's disease gene on chromosome 12q23-24.1. American Journal of Medical Genetics: Neuropsychiatric Genetics (in press).

Parfitt, E., Burge, S., Craddock, N., et al (1994) The gene for Darier's disease maps between D12S78 and D12S79. Human Molecular Genetics, 3, 35-38.

Nicholas Craddock PETER McGufFin MiChAEL OWEN

Department of Psychological Medicine

University of Wales College of Medicine Cardiff CF4 4XN 